\title{
LA INTERPRETACIÓN DE LA CLÁUSULA EIUS REI NOMINE DE LOS EDICTOS DE EXERCITORIA Y DE INSTITORIA ACTIONE
}

\author{
THE CLAUSE EIUS REI NOMINE OF THE DE EXERCITORIA AND DE \\ INSTITORIA ACTIONE AND ITS INTERPRETATION
}

\section{Patricio Lazo*}

\begin{abstract}
RESUMEN: El trabajo centra su atención en la interpretación que los juristas romanos hicieron de la cláusula eius rei nomine del edicto pretorio que concedía las acciones institoria y exercitoria. Específicamente, se detiene en la protección conferida a los acreedores por las obligaciones contraídas por los dependientes del dominus, en la medida que su gestión se circunscribía los negocios propios del dominus. El trabajo examina la forma en que la interpretación jurisprudencial de los requisitos previstos en el edicto delimitó cuidadosamente la responsabilidad contractual de aquel.
\end{abstract}

Palabras clave: Praepositio, actio exercitoria, actio institoria, responsabilidad in solidum.

\begin{abstract}
This article focuses on the interpretation construed by that roman lawyers on the eius rei nomine clause by which the pretorian edict granted the insitoria and exercitoria actions. Specifically this article pays attention to the protection that the praetor offered to creditors due to obligations incurred by dependents of the dominus, insofar as their practices restricted to the bussiness of the dominus. The article analizes the way that legal interpretation of the edictal requirements circumscribed the contractual liability of the dominus.
\end{abstract}

Key words: Praepositio, actio exercitoria, actio institoria, in solidum liability.

\section{INTRODUCCIÓN}

$\mathrm{Al}$ explicar Gayo las fórmulas de las acciones exercitoria e institoria, indica contra quién se conceden y bajo qué supuestos. La primera se daría "cum pater dominusue flium seruumue magistrum naui praeposuerit et quid cum eo eius rei gratia, cui praepositus fuerit, [negotium] gestum erit" (Gai. 4,71) es decir, contra el pater o dominus si este hubiese, en virtud de la respectiva praepositio colocado a un hijo o un esclavo suyos como patrón o

Profesor Asociado de la Escuela de Derecho de la Pontificia Universidad Católica de Valparaíso. Dirección postal: Avenida Brasil 2950, Valparaíso. Correo electrónico: patricio.lazo@ucv.cl

Este trabajo forma parte de los proyectos FONDECYT No 1120606 "Limitación de la responsabilidad contractual. Perspectivas teórica y metodológica de un dogma de origen romano" y ANILLO-CONICYT "Estudios históricodogmáticos de Derecho patrimonial privado: Una mirada a los artículos de los libros II y IV del Código Civil de Chile", código soc 1111. El autor agradece los comentarios y observaciones, realizadas en el contexto de seminarios realizados en Valparaíso, Amsterdam y Madrid, de los profesores Christian Baldus (Universidad de Heidelberg), Hans Ankum (Universidad de Amsterdam), Laurens Winkel (Universidad de Rotterdam) y Eric Pool (Universidad de Amsterdam), Ana Martín-Minguijón, Federico Fernández de Buján y Manuel García Garrido. Los errores que este trabajo pueda contener corren por cuenta exclusiva del autor. 
capitán de una nave, y por los negocios concluidos por estos que fueren concernientes a la misma (eius rei gratia). Respecto de la institoria, señala que esta acción se concedería "cum quis tabernae aut cuilibet negotiationi filium seruumue suum uel quemlibet extraneum, siue seruum siue liberum, praeposuerit et quid cum eo eius rei gratia, cui praepositus est, contractum fuerit", es decir, contra quien, en la respectiva praepositio, hubiese colocado a su hijo o esclavo, como también a un extraño, fuere libre o esclavo, a cargo de un establecimiento comercial, por las obligaciones que hubiesen contraído concernientes a su objeto ${ }^{1}$. Asimismo, de ambas acciones Gayo hace idéntica afirmación: estas acciones harían efectiva en el pater o dominus su responsabilidad in solidum ${ }^{2}$, es decir, por el total de la deuda contraída. Este tipo de responsabilidad respecto de la actio exercitoria es la que mueve a Gayo a hacer un elogio de la misma, indicando que su creación era muy justa (aequissimum).

La exposición de Gayo remite al edicto del pretor en el cual se consagraban ambas acciones, especialmente a su régimen de responsabilidad.

Es posible identificar como un elemento de primera importancia a la praepositio, es decir, al acto del pater o dominus que, para servirnos de los términos usados por Miceli ${ }^{3}$, constituye la legitimación inicial del gestor frente a los terceros, de modo que permite identificar genéricamente la actividad que es llamado a desarrollar, y a resultas de la cual queda un subordinado del pater o dominus -al menos, en principio- a cargo de la gestión de la nave o del establecimiento comercial ${ }^{4}$. Como un "un acto de 'puesta al frente' de un establecimiento marítimo o terrestre" lo ve Valiños, mientras que Petrucci sugiere que ella es

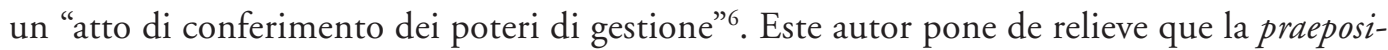
tio constituye el elemento central sobre el cual se apoya la responsabilidad, porque permite al empresario o 'preponente' delimitarla por medio de la fijación de reglas sobre el ejercicio de dichos poderes y sobre los contratos concluidos por el institor ${ }^{7}$, entre las que se incluye el establecimiento de prohibiciones ${ }^{8}$. Como veremos, la jurisprudencia desplegó una inten-

\footnotetext{
1 Las expresiones eius rei nomine y eius rei gratia, que aparecen en las fuentes, he preferido designarlas como 'concernientes a la nave', en el caso de la acción exercitoria y como 'concernientes a su objeto', tratándose de la institoria. Las expresiones latinas, como puede verse, son lo suficientemente amplias, atendidas las múltiples acepciones de la voz res. Al traducir de esta forma creo no solo no haber distorsionado el sentido de la expresión latina, sino haber acercado su sentido a los términos del derecho moderno.

2 Una reciente discusión acerca de los sentidos en que esta clase de responsabilidad podría interpretarse, especialmente en las fuentes relativas a la actio exercitoria, en GARCía GarRIdO (2010) p. 2.

3 Miceli (2001) pp. 33 y 353; Miceli (2002) p. 86; Miceli (2008) p. 80 s. Como "un acto de investidura lo calificó Serrao (1971) p. 829. Más adelante, Serrao (1989) p. 20 la vería también como uno de los niveles de gradación (precisamente el máximo), de una situación que involucra a la scientia (el grado mínimo) y la voluntas (el grado intermedio)".

4 Pugliese (1957) p. 310 ss.; Valiño (1967) p. 356 ss.; Wacke (1994) p. 304; Petrucci (2007) p. 12 ss.; Miceli (2001) p. 188; Miceli (2008) p. 67 ss. y 80 s.; Cerami-Petrucci (2010) p. 56 ss.

5 VALIÑo (1967) p. 356. En p. 361 el mismo sostiene, ahora a propósito de la praepositio institoria, que ella "significa colocación para funciones permanentes".

6 Petrucci (2007) p. 21

7 Petrucci (2007) p. 26. Véase también Wunner (1964) pp. 114 ss.; Valiño (1967) p. 356 ss.; CeramiPetrucci (2010) p. 60. A su turno, Aubert (1994) p. 11 s., describe la forma en que era otorgada la praepositio a partir de los documentos encontrados entre los papiros griegos del Egipto romano.

8 Véase Petrucci (2007) p. 14 ss.; Aubert (1994) p. 53 s.; Miceli (2001) p. 192 ss.
} 
sa labor para deslindar, precisamente, los supuestos a los que se se refiere nuestra autora. Con todo, para Miceli no se trataría del la única fuente de responsabilidad en juego, al menos para el proponente, sino de un acto más bien inicial, en el que se identifica la actividad negocial que desarrollará el dependiente solo genéricamente, puesto que su contenido específico se pondrá de manifiesto en la actividad a desarrollar?

De este modo, la praepositio desempeña un papel central para determinar la responsabilidad del empresario, la que no queda, por consiguiente, sujeta a la relación potestativa que lo une al dependiente. Esto es así al punto de que podría decirse que si la praepositio no existiese, los actos y negocios jurídicos concluidos por un dependiente no podrían servir de base para la concesión de las acciones institoria o exercitoria, aunque se constatase la existencia de la respectiva relación potestativa e incluso de los negocios jurídicos concluidos por el dependiente.

La praepositio reconoce, entonces, entre sus fines, la realización de un cierto abanico de negocios jurídicos que pueden estar señalados en ella con una precisión variable ${ }^{10}$. Es decir, se encargaría a un exercitor o a un institor concluir ciertos negocios jurídicos, los cuales, solo en la medida que tuviesen relación con el objeto de los negocios de la nave o del establecimiento de comercio, podrían servir de supuesto para hacer efectiva la responsabilidad in solidum de quien hubiese 'prepuesto' a tales dependientes. En este orden de ideas Wacke ha sugerido que a partir de la expresión "eius rei nomine cui praepositus fuisset", lo exigido no es un negocio en nombre del empresario, sino que dicho acto se circunscriba a la esfera negocial (Geschäftsgebiet) que se ha atribuido al institor. Este hecho, sumado a la praepositio serían los aquellos exigidos en el derecho clásico para hacer efectiva la responsabilidad in solidum ${ }^{11}$.

De esta guisa, los negocios jurídicos en los que cabía participación a los dependientes debían no solo fundarse en la praepositio, sino que, en aquellos casos en que esta no fuese suficientemente detallada, ser susceptibles de ser subsumidos en las negociaciones para las cuales la nave era empleada -o bien, en su caso, para aquellas para las que el establecimiento de comercio era destinado-. La cláusula eius rei nomine resultaba ser clave en este sentido ${ }^{12}$ y los juristas romanos, en particular de la época alto-clásica llevarían adelante un trabajo interpretativo de hondo calado, para decidir bajo qué supuestos se satisfacía la exigencia de la cláusula edictal. Mostrar cómo, ante la necesidad de fundar decisiones de inclusión y exclusión en la praepositio de determinados negocios jurídicos, la jurisprudencia se valió de ciertas criterios de decisión -controvertidos algunos de ellos- es el objeto principal de este trabajo.

En lo que sigue, me referiré a los edictos que consagraban las acciones exercitoria e institoria (2) y los textos que configuraron a base textual de la reconstrucción de ellos (3). Finalmente (4) centraré la atención en casos de mutuo que plantearon dificultades a los ju-

\footnotetext{
Miceli (2002) p. 82.

10 Miceli (2008) p. 71; Cerami-Petrucci (2010) p. 60.

11 WACKE (1994) p. 336.

12 Lenel (1896) p. 136.
} 
ristas alto-clásicos ${ }^{13}$ y exigieron de ellos la creación de criterios que permitieran avanzar en la decisión de conceder o no la respectiva acción.

\section{LOS EDICTOS}

Punto de partida de la labor interpretativa de la jurisprudencia fue un texto, que, como se adelantó, corresponde a los edictos de exercitoria actione y de institoria actione, ambos contenidos en el Título XVIII del Edicto Perpetuo ${ }^{14}$. De acuerdo con la redacción que Lenel conjetura para cada uno, se observan pocas diferencias ${ }^{15}$ :

\begin{tabular}{|l|l|}
\hline \multicolumn{1}{|c|}{ de exercitoria actione } & \multicolumn{1}{|c|}{ de institoria actione ${ }^{16}$} \\
\hline Quod cum magistro navis gestum erit eius rei & Quod cum institore gestum erit eius rei \\
nomine, cui ibi praeposuerit fuerit, in eum, & nomine, cui praepositus fuerit, in eum, qui \\
qui eam naves exercuerit, iudicium dabo ${ }^{17}$. & eum praeposuerit, iudicatum dabo ${ }^{18}$. \\
\hline
\end{tabular}

Difieren ambos edictos, como es lógico, en la tipificación del dependiente en cada caso: magister navis, en el de la exercitoria; institor, en el de la institoria. La legitimación pasiva parece ser más amplia en el caso de la primera, ya que, en tanto en el edicto de ins-

13 Para el esquema de periodización de la jurisprudencia se ha preferido utilizar en este trabajo aquella fundada en cuestiones estilísticas, común en la romanística en lengua alemana y, ciertamente, adoptada en el Handbcuh de Kaser (1971 y 1975) antes que la basada en ciclos políticos (República y dinastías imperiales). Ello se aviene mejor con la atención que aquí quiere dispensarse a las formas que adopta el pensamiento pensamiento y a las diferencias que, conforme a ello, pueden apreciarse entre los juristas.

14 Su rúbrica habría sido la siguiente: Quod cum magistro navis, institore eove, qui in aliena potestate erit, negotium gestum erit. Como se verá, la cláusula negotium gestum erit se proyecta, si bien no en forma idéntica, en ambos edictos. Sobre la expresión negotia gerere, vid. GuZMÁn BRITO (2005) p. 26 para quien esta expresión equivale a "llevar o gestionar negocios". A su juicio, esta acepción técnica de la expresión parece conservarse en la cláusula edictal 'negotium gestum (cum)', aunque ella debe ser entendida en el sentido de 'gestionar', pero en cuanto contraparte del magister navis o el institor y no conjuntamente con ellos.

15 Tratándose del primer edicto, las fuentes ofrecieron a Lenel una base textual más difusa que para el segundo. Para este último bastó a Lenel solo un fragmento de Ulpiano para conjeturar su redacción: "der Kommentar Ulpians, auch hier unsere Hauptquelle, ergibt-kaum irgend zweifelhaft-folgende Ediktsworte". LENEL (1927) p. 258.

16 Lenel (1927) p. 257 ss. En todo caso, debe tenerse en cuenta que las recientes investigaciones en torno al edicto pretorio, sugieren que los edictos comprendidos dentro de un título no llevaban rúbrica; véase DomINGO (1992) p. 10 s. El orden conforme al cual Lenel presenta a las acciones, reflejaría también el orden de aparición en la historia romana de ellas. Véase Solazzi (1963) p. 241 s. Por el contrario, De Ligt (1999) p. 224 ss. postula un orden diferente, comenzando por la actio de peculio y terminando con las acciones exercitoria e institoria.

${ }_{17}$ Trad.: "Daré acción contra aquel que explotase la nave por los negocios que se hubiesen contraído con un patrón de nave, por causa de los asuntos para los cuales aquel fue colocado (al frente de los negocios)”. Es evidente que la expresión praepositus no encuentra un término equiparable en lengua española. La expresión 'prepuesto', aunque la utilizamos aquí, es extraña al lenguaje negocial moderno de Chile. En este caso, como en la traducción de la nota siguiente, hemos optado por una expresión que, sin ser técnica, permite aproximarse al contenido de la voz praepositus. Como podrá verse en otras traducciones que ofrecemos, en ocasiones las palabras elegidas aproximan el concepto al de mandatario, confusión esta que debe evitarse.

18 Trad.: "Daré acción contra aquel que explotase la nave por los negocios que se hubiesen contraído con un patrón de nave, por causa de los asuntos para los cuales aquel fue colocado (al frente de los negocios)". 
titoria actione el demandado es "eum, qui eum praeposuerit", es decir, aquel que designó al institor, en el caso del de exercitoria actione el demandado es "eum, qui eam naves exercuerit" y no necesariamente quien hubiese colocado (praeposuerit) al magister a cargo de la nave. Salvo estas dos diferencias, ambos edictos contienen una cláusula idéntica: "quod...gestum erit eius rei nomine, cui ibi praeposuerit fuerit". Se trata, como lo adelantamos, de un aspecto central del régimen de responsabilidad del edicto: el legitimado pasivo al que ya hemos hecho somera referencia, lo será en razón de haberse contraído negocios jurídicos con el dependiente (exercitor, institor) que tuviesen directa relación con la actividad para la cual se le designó. En otras palabras, los edictos circunscriben el alcance de cada una de las acciones a determinadas negociaciones, las cuales, a su vez, se fundan en una praepositio.

\section{BASE TEXTUAL DE LA CLÁUSULA EDICTAL}

La cláusula del edicto relativa a los contratos concluidos por el magister navis la reconstruye Lenel a partir de sendos pasajes de Ulpiano, extraídos del libro 28 de comentarios al edicto y de Gayo:

De exercitoria actione: a) D. 14,1,1,7 (Ulp. 28 ad ed.): Non autem ex omni causa praetor dat in exercitorem actionem, sed eius rei nomine, cuius ibi praepositus fuerit, id est si in eam rem praepositus sit, ut puta si ad onus vehendum locatum sit aut aliquas res emerit utiles naviganti vel si quid reficiendae navis causa contractum vel impensum est vel si quid nautae operarum nomine petent ${ }^{19}$; b) Gai. 4,71: tunc autem exercitoria locum habet, cum pater dominusue filium seruumue magistrum naui praeposuerit et quid cum eo eius rei gratia, cui praepositus fuerit, [negotium] gestum erit. cum enim ea quoque res ex uoluntate patris dominiue contrahi uideatur, aequissimum esse uisum est in solidum actionem dari; quin etiam licet extraneum quisque magistrum naui praeposuerit, siue seruum siue liberum, exercitoria actio in eum redditur. ideo autem exercitoria actio appellatur, quia exercitor nocatur is, ad quem cotidianus nauis quaestus peruenit ${ }^{20}$.

De institoria actione: a) D. 14,3,5,11 (Ulp. 28 ad ed.): Non tamen omne, quod cum institore geritur, obligat eum qui praeposuit, sed ita, si eius rei gratia, cui praepositus fuerit, contractum est, id est dumtaxat ad id quod eum praeposuitt; ; b) D. 14,3,5,15 (Ulp. 28 ad

19 "No por cualquier asunto da el pretor acción contra el naviero, sino por razón del negocio que fue encomendado al patrón, es decir, si hubiese este hubiese sido puesto para aquel negocio, como por ejemplo, si se hubiese arrendado el transporte de mercancías, o si hubiese comprado algunas cosas útiles para la navegación, o si se contrató o se gastó algo para reparar la nave, o si la tripulación pidiera algo por sus servicios". La traducción corresponde a la de D'Ors et al. (1968).

20 "La primera se da cuando el padre o el dueño han colocado al hijo o al esclavo de patrón de una nave y se ha hecho algún negocio referente a la nave con el patrón. Pues como ese negocio parece que se ha hecho con la voluntad del padre o del dueño, se estimó muy justo que se diera contra aquellos una acción sin limitaciones. Es más, aunque el pratrón encargado fuere una persona extraña, ya libre, ya esclava, aquella acción pretoria se da de todos modos contra aquellos. Y se llama acción del patrón, porque se llama patrón el que recauda las ganancias cotidianas de la nave". La traducción corresponde a la de D’ORS (1998); salvo este caso y aquellos otros en que se indique expresamente, las traducciones de pasajes del Digesto ofrecidas son del autor de este trabajo, quien ha tenido a la vista las de D’Ors (citada) y la de García del Corral.

21 Trad.: "Pero no todo lo que se negoció con el factor obliga al que lo puso, sino de este modo, si se contrató en razón de aquel asunto para el cual hubiese sido encargado, esto es, solamente para aquello por lo que lo puso al frente". 
ed.): Item si institor, cum oleum vendidisset, anulum arrae nomine acceperit neque eum reddat, dominum institoria teneri: nam eius rei, in quam praepositus est, contractum est: nisi forte mandatum ei fuit praesenti pecunia vendere. quare si forte pignus institor ob pretium acceperit, institoriae locus erit22; c) Gai. 4,71: institoria nero formula tum locum habet, cum quis tabernae aut cuilibet negotiationi filium seruumue suum uel quemlibet extraneum, siue seruum siue liberum, praeposuerit et quid cum eo eius rei gratia, cui praepositus est, contractum fuerit. ideo autem institoria nocatur, quia qui tabernae praeponitur, institor appellatur. quae et ipsa formula in solidum est ${ }^{23}$.

La estructura del comentario ulpianeo recogido en D. 14,1,1,7 tiene, claramente, dos partes: en la primera, el comentario a la cláusula eius rei nomine, cuius ibi praepositus fuerit; en la segunda, y a continuación del giro id est, algunos ejemplos. La importancia asignada por Lenel a este fragmento, a propósito del edicto de exercitoria actione, no puede extrañar. Lenel juzga que el período eius-fuerit constituye una transcripción de la cláusula del edicto que nos ocupa y esta hipótesis parece verosímil, especialmente si se atiende al hecho de que en el texto gayano (Gai. 4,71) encontramos una frase muy similar: eius rei gratia, cui praepositus fuerit. La comparación entre ambos pasajes debe entonces hacerse cargo de esta similitud. Y el origen de ella podría encontrarse en el hecho de que tanto Gayo como Ulpiano leen el mismo edicto y, por consiguiente, transcriben sus palabras con mínimas modificaciones. Y no obsta a esta consideración, al menos en lo que al texto gayano se refiere, su carácter institucional, ya que este solo hecho no habría impedido al autor echar mano de un estilo propio de la literatura de comentarios, el que, por lo demás, no le era desconocido. De modo que habría que descartar que la similitud entre una y otra obra, en lo que a esta frase se refiere, sea casual. Más aún, parece verosímil que el origen de esta se encuentre en el mismo texto que se comenta, es decir, el edicto ${ }^{24}$.

Sin embargo, las coincidencias llegan hasta ahí. En tanto Ulpiano continúa su comentario señalando un brevísimo elenco de contratos comprendidos en la praepositio y que, en consecuencia, quedan amparados por el edicto, Gayo opta por referirse a la responsabilidad que nace para el exercitor, derivada de la praepositio del magister navis y de los negocios por él concluidos. Volveremos sobre esto más adelante ${ }^{25}$.

Veamos ahora el edicto de institoria actione. Lenel ${ }^{26}$ advierte en la información proporcionada por Ulpiano una transcripción de la cláusula edictal que nos ocupa, aunque, como veremos, ella es un poco menos literal que en el caso del edicto de la actio exercitoria.

\footnotetext{
22 Trad.: "Del mismo modo, si el factor hubiese vendido aceite y recibido un anillo a título de arras y no lo devolviera, queda obligado el dueño por la acción institoria: porque se contrató por causa de aquel asunto para el cual fue encargado, a no ser que se le haya encargado vender al contado. Por lo cual, si el factor hubiese recibido algo en prenda en lugar de precio, tendrá lugar la acción institoria”.

23 Trad. "La fórmula de la institoria tiene lugar cuando uno ha colocado para la gestión de la empresa o cualquier otra negociación a un hijo o un esclavo suyos, o bien a uno ajeno, sea hijo o esclavo, y por los negocios que con este, por causa de este asunto, se hayan contraído. Se llama institoria, porque quien ordena en la empresa se llama institor. Esta acción es in solidum".

24 Una exégesis del fragmento, en Petrucci (2007) p. 60 ss. En p. 61 este autor remarca que la publicidad de la praepositio no venía exigida en el texto edictal y que su elaboración y desarrollo fue labor de la jurisprudencia. Sobre D. 14,3,5,11, véase WACKE (1994) p. 327.

25 Véase apartado 4.

26 LeNEL (1927) p. 258, n. 11.
} 
Si los razonamientos anteriores son correctos, entonces en D. 14,3,5,11 la expresión eius rei gratia, cui praepositus fuerit, contractum est correspondería a una transcripción de la cláusula edictal respectiva. En cuanto a la estructura del fragmento, se advierte una diferencia con D. 14,1,1,7, dado que a continuación de la expresión id est, Ulpiano, en lugar de exponer una lista de negocios, afirma que los actos que obligan al que designó al institor son aquellos que se refieren al asunto para el cual este fue nombrado. Y debe observarse que un período casi idéntico (eius rei, in quam praepositus est, contractum est) aparece reiterado en D. 14,3,5,15. La diferencia con $\$ 11$ es mínima: tan solo la expresión gratia desaparece en este caso. Precisamente es esta expresión la que Lenel reemplaza en la reconstrucción del edicto, por nomine. Si se compara, a continuación, con el texto de Gai. 4,71, vemos que una frase idéntica a la de $\$ 11$ remite a los términos del edicto: et quid cum eo rei gratia, cui praepositus est, contractum fuerit.

Lenel, por consiguiente, al momento de elaborar su reconstrucción, opta por una redacción que, aunque conservando la mayor parte de lo transmitido en los textos ulpianeo y gayano, reemplaza gratia por nomine y coloca, en lugar de la expresión contractum est o fuerit-que se repite en tres pasajes de la institoria- la de gestum erit, haciéndola preceder del período eius-fuerit.

¿Se justifican estas decisiones reconstructivas de Lenel? Pensamos que, en gran medida, sí: supuesto que a ambos edictos daba inicio la expresión quod, la sintaxis de cada uno exigía una inmediata referencia a la negociación, para lo cual Lenel elige, como ya dijimos, la expresión gestum erit. En cuanto a esto último, se observa que nuestro autor opta por el participio de gerere, esto es, gestum, y no, en cambio, por el participio de contrahere (contractum). Pero debe observarse que este último participio se repite en las fuentes citadas; desde esa perspectiva, cabría la pregunta del por qué de la preferencia de Lenel por gestum, en desmedro de contractum, para su reconstrucción ${ }^{27}$. Sobre este punto, las explicaciones que han sido ofrecidas admiten apenas un matiz de diferencia: Valiño ha sostenido que entre ambos verbos, contrahere y gerere, existe sinonimia ${ }^{28}$; en tanto que Wunner, sin llegar a afirmar tal situación, cree que la mayor parte de los casos de ambas acciones se refieren a responsabilidad contractual, siendo muy pocos aquellos en los que el gerere del institor remitiría a una responsabilidad nocontractual ${ }^{29}$. Desde este punto de vista, la reconstrucción leneliana sería acertada.

\section{ULPIANO Y LA ESTRATEGIA DE LA TIPIFICACIÓN CONTRACTUAL}

En el apartado anterior hacíamos ver la existencia de ciertas diferencias entre lo que ponían de relieve Ulpiano, por un lado y Gayo, por otro, a propósito del edicto. Pues bien,

\footnotetext{
27 Guzmán Brito afirma que "el verbo contrahere prácticamente carece de todo tecnicismo específico y que, en general, es utilizable para indicar, bien la celebración de un acto, bien su resultado, es decir, la relación generada misma. Este sentido aparece usado en el edicto del pretor..." (GuZMÁn Brito, 2005, p. 35). Gayo lo utiliza profusamente y con diferentes funciones, pero en lo que nos concierne, esto es, en el sentido de concluir un negocio jurídico protegido mediante acciones adyecticias, lo vemos empleado en D. 14,3,2 (eo nomine, quo institor contraxit), en D. 14,5,1 (omnia proconsul agit, ut qui contraxit cum eo) y en D. 15,1,27pr. (et si in rem versum est, quod iussu patris dominive contractum sit).

28 VALIÑo (1968) p. 378.

29 WUNNER (1964) p. 107.
} 
¿qué podría explicar la diferente perspectiva que adopta el análisis en cada uno de ellos? En mi opinión, una posibilidad es que tal diferencia tenga que ver con los aspectos que cada jurista entienda como central para la interpretación del edicto. Es decir, en tanto Gayo se inclinaría a poner de relieve aspectos de orden volitivo (cum enim ea quoque res ex uoluntate patris dominiue contrahi uideatur), en Ulpiano se observaría una tendencia que, sin dejar aquellos de lado, se encaminaría hacia una estrategia de tipificación de los supuestos de procedencia de las acciones. D.14,1,1,7 sería un muy buen ejemplo de ello: se trata de un fragmento en el que Ulpiano elabora un listado de negociaciones, con la consecuencia de que, procediendo así, singulariza los supuestos típicos que quedan comprendidos en la amplia redacción de la cláusula edictal relativa a la acción exercitoria. De esta forma, los contratos de arrendamiento de transporte de carga, de compra de aparejos de navegación, aquellos contraídos con ocasión de la reparación de la nave y, junto a ellos, el pago por los servicios de la tripulación pasarían a constituir negocios cuya conclusión se relaciona directamente con aquellos que, por concernir a la nave, se encargan a un magister (navis). Hay que observar que una lista similar de negocios la consigna el mismo Ulpiano en un parágrafo precedente (me refiero a D. 14,1,1,3, que se transcribe más abajo), en el que señala entre los contratos cuya gestión se suele nombrar patrones, a los siguientes: transporte de mercancías y pasajeros, compra de aparejos y compraventa de las mercancías transportadas. Si, a continuación, reparamos en la actitud que adopta Ulpiano a propósito de D.14,3,5,12, relativo a la actio institoria, notaremos que igualmente se ocupa de nombrar aquellos negocios que hacen procedente la acción, así como también aquellos en que ello no ocurriría:

D. 14,1,1,3 (Ulp. 28 ad ed.): Magistri autem imponuntur locandis navibus vel ad merces vel vectoribus conducendis armamentisve emendis: sed etiamsi mercibus emendis vel vendendis fuerit praepositus, etiam hoc nomine obligat exercitorem ${ }^{30}$.
D.14,3,5,12 (Ulp. 28 ad ed.): Proinde si praeposui ad mercium distractionem, tenebor nomine eius ex empto actione: item si forte ad emendum eum praeposuero, tenebor dumtaxat ex vendito: sed neque si ad emendum, et ille vendiderit, neque si ad vendendum, et ille emerit, debebit teneri, idque Cassius probat ${ }^{31}$.

Pues bien, Gayo, como hemos visto, apunta en una dirección distinta. Diríase que su interés, expresado a propósito de ambas acciones en Gai. 4,71, consistiría en poner de manifiesto el régimen de responsabilidad ilimitada que afectaría al pater o dominus, a propósito de estas dos acciones y cuán justo ello sería. Su comentario -didáctico, por cierto- alecciona en torno al efecto principal de la acción y a su presupuesto principal, pero

\footnotetext{
30 Trad.: "Se dan patrones para: dar en arriendo las naves, las mercancías, conducir pasajeros y comprar aparejos. Pero, aunque hubiese sido puesto para comprar o vender mercancías, también por esta causa se obliga el naviero".

31 Trad.: "Luego, si lo puse para la venta de mercancías, estaré obligado en nombre del negocio por la acción de la compra. Asimismo, si lo hubiese puesto para comprar, me obligaré tan solo por la acción de la venta. Pero si (lo hubiese colocado) para comprar, él vendiese, o para vender, él comprase, no estaré obligado, lo que aprueba Casio".
} 
sin profundizar. Así, las diferencias con Ulpiano conducirían a resultados interpretativos distintos, en virtud de los cuales se trasladaría el centro de gravedad de la procedencia de la acción desde la voluntad (Gayo) hacia la tipificación contractual (Ulpiano). El jurista tardoclásico reforzaría una idea recurrente a propósito de ambos edictos: la de que no todos los negocios jurídicos obligatorios en los que se ha constituido como contraparte el patrón de nave (como ocurre en D. 14,1,1,3) o el factor de comercio (caso de D. 14,3,5,12) obligan al exercitor o a quien designó al institor. De este modo, que Ulpiano dé comienzo a D. 14,1,1,7 con la advertencia non autem ex omni causa praetor dat in exercitorem actionem; y que lo propio haga en D. 14,3,5,11 con la frase non tamen omne, quod cum institore geritur, obligat eum qui praeposuit, no sería casual y revela una preocupación por resolver problemas interpretativos muy concretos, probablemente provenientes de la práctica. En mi opinión, los problemas que juristas predecesores de Ulpiano debieron enfrentar a propósito del mutuo, constituirían un buen ejemplo de ello.

\section{EL MUTUO Y SU PROBLEMÁTICA TIPIFICACIÓN COMO ACTO CONCERNIENTE A LAS NEGOCIACIONES}

El edicto, tal como se ha podido apreciar, ofrecía un campo de acción para la interpretación jurisprudencial tan atrayente como vasto. Se sigue de su lectura que la concesión de cada una de las acciones contra el naviero o contra el empresario se sujeta a dos requisitos: el primero de ellos, que el dependiente hubiese sido colocado por aquel para hacerse cargo del negocio, marítimo o terrestre; el segundo, que la actuación del dependiente se hubiese enmarcado en los asuntos relativos al negocio del cual quedaba a cargo, conforme a lo previsto en la praepositio. Pero la interpretación de la cláusula edictal eius rei nomine adquiría una especial relevancia cuando los términos de la prepositio no eran suficientes. Así las cosas, la exacta delimitación entre aquellos negocios concernientes a la empresa naviera, en el caso del magister navis, y a la terrestre, en el caso del institor, tendría una relevancia no menor, por cuanto la posible exclusión de algunos de estos negocios de dicha esfera haría improbable, si no imposible, la concesión de la acción.

Uno de los negocios que exigió de la jurisprudencia un análisis minucioso de su grado de pertinencia con la nave o el negocio terrestre la proporcionó el mutuo. Desde luego, no faltaba razón para ello, ya que uno de los problemas más comunes de quienes se hacían cargo de negocios terrestres y marítimos era el de la financiación de sus actividades. De esta forma, el mutuo dinerario dio ocasión a la jurisprudencia para resolver el problema de su adecuación a lo previsto en la cláusula eius rei nomine. Con base en el testimonio de D.14,3,5,13 (Ulp. 28 ad ed.) podría concluirse que para el mutuante que quisiese demandar con la institoria bastaría probar la praepositio: Sed si pecuniam quis crediderit institori ad emendas merces praeposito, locus est institoriae, idemque et si ad pensionem pro taberna exsolvendam: quod ita verum puto, nisi prohibitus fuit mutuari ${ }^{32}$. Sin embargo, la situación era en

\footnotetext{
32 Trad.: "Pero si alguno hubiese prestado dinero al factor de comercio puesto para comprar mercancías, tiene lugar la acción institoria. Y lo mismo, también si para pagar el alquiler de la tienda; lo que tengo por verdadero de este modo si no se le prohibió que tomase en mutuo".
} 
realidad más compleja, como lo prueba el hecho de que el propio Ulpiano expuso casos en los que el problema vinculaba a la praepositio, con la exacta correspondencia entre la causa del mutuo y el uso que se hacía del dinero. Si no existía correspondencia -al ser utilizado el dinero para un fin distinto- entonces los juristas debían examinar cuidadosamente las circunstancias que rodeaban al mutuo. Como veremos, a continuación, esta mirada se extendió también a la diligencia del acreedor.

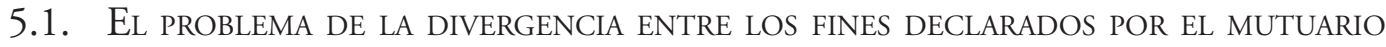 \\ Y PATRÓN DE NAVE Y EL USO QUE EFECTIVAMENTE DIO AL DINERO OCUPA UN LUGAR PREPONDERANTE EN EL SIGUIENTE FRAGMENTO:}

D.14,1,1,8-9 (Ulp. 28 ad ed.): Quid si mutuam pecuniam sumpserit, an eius rei nomine videatur gestum? et Pegasus existimat, si ad usum eius rei, in quam praepositus est, fuerit mutuatus, dandam actionem, quam sententiam puto veram: quid enim si ad armandam instruendamve navem vel nautas exhibendos mutuatus est? (9) Unde quaerit Ofilius, si ad reficiendam navem mutuatus nummos in suos usus converterit, an in exercitorem detur actio. et ait, si hac lege accepit quasi <mutuatus nummos> in navem impensurus, mox mutavit voluntatem, teneri exercitorem imputaturum sibi, cur talem praeposuerit: quod si ab initio consilium cepit fraudandi creditoris et hoc specialiter non expresserit, quod ad navis causam accipit, contra esse: quam distinctionem Pedius probat ${ }^{33}$.

El problema que Ulpiano somete a análisis es determinar si la celebración de un mutuo dinerario se enmarca en la actuación dentro de los negocios por cuya causa se debía

\footnotetext{
33 Trad.: "Si hubiese tomado dinero en mutuo, ¿se entenderá que ha obrado en por causa del mismo cargo. Pegaso opina que si hubiese tomado en mutuo para el asunto para el que había sido colocado (al frente de la nave), se ha de dar la acción, opinión que juzgo verdadera. Porque ¿qué se habrá de decir si tomó el mutuo para armar o proveer la nave o procurarse marineros? (9) Por lo cual pregunta Ofilio, si habiendo recibido dinero en mutuo para reparar la nave lo hubiese aplicado a su propio uso, ¿se dará acción contra el naviero? Y dice que si lo recibió con una cláusula del tipo "los dineros mutuados habrán de ser invertidos en la nave” y luego cambió de voluntad, el naviero se habrá de culpar a sí mismo de quedar obligado, por haber empleado a tal individuo, pero que, si desde el principio tomó la decisión de defraudar al acreedor, y no hubiese expresado especialmente que lo recibió por causa de la nave, es al contrario, distinción que aprueba Pedio”. Esta traducción difiere de las de García del Corral y de D’Ors, en cuanto al valor asignado a la expresión quasi. Estos traducen: "Y dice que si lo recibió con esta obligación, como para haberlo de invertir en la nave...” (García del Corral), o bien "Y dice que, si el patrón lo recibió con la obligación de invertirlo en la nave...” (D’Ors). La opción por la traducción que ofrezco, con el entrecomillado de la frase "los dineros mutuados habrán de ser invertidos en la nave" implica enteder que se trata de la reproducción de una cláusula agregada al mutuo, lo que permite diferenciar en el texto la descripción del caso de la cláusula que se cita (período quasi-impensurus). La expresión quasi, que es la que introduce la cláusula de la que se viene hablando, puede tener, según HACKL (1999) p. 118 ss., una doble función: o bien una relativa a la comparación, o bien una ficcional, más cercana a las expresiones "como si", que es la que, a mi juicio, el texto emplea, aunque en la traducción me valgo de la expresión "del tipo", como equivalente. Sobre el sentido de "cláusula de destinación” de la expresión hac lege, véase Cerami (1999) p. 273
} 
conceder la acción ${ }^{34}$. En el pasaje vienen reportadas las opiniones de Ofilio ${ }^{35}$ y Pegaso $^{36}$, aparte de la del propio Ulpiano. Además, hay una referencia a Pedio, uno de los juristas que habrían adherido a Ofilio, pero nada más se agrega. La sola cita de cuatro juristas da cuenta de cómo el caso debió ser objeto de un continuo tratamiento, así como de su importancia. Todavía más, constituye un importante atestado acerca de cómo la jurisprudencia romana buscó delimitar con un alto grado de precisión la concesión de la acción.

En lo que sigue me refiero a las opiniones Ofilio y Pegaso.

Ofilio, cuya opinión es expuesta en el $₫ 9$, a continuación de la de Pegaso ( $\$ 8)$, planteó el supuesto consistente en que un patrón de nave hubiese recibido un mutuo de dinero con el fin de destinarlo a la reparación de la nave ${ }^{37}$ y que, una vez obtenido, lo hubiese utilizado en su propio beneficio (si ad reficiendam navem mutuatus nummos in suos usus converterit). En tal caso, sostuvo Ofilio, el naviero queda igualmente obligado por la acción (teneri exercitorem). Nuestro jurista, por consiguiente, justifica la concesión de la acción sobre la base de que la causa (ad reficiendam navem) por la cual se pide el prestamo se relaciona directamente con la nave ${ }^{38}$, a pesar de que, con posterioridad y de forma unilateral, el magister navis cambie de opinión y utilice el dinero en algo completamente ajeno a ella. Este esquema de solución fue seguido por Pedio, según informa Ulpiano. A su turno, Pegaso (\$ 8) aborda un supuesto similar (si ad usum eius rei, in quam praepositus est, fuerit mutuatus, dandam actionem), pero excluye la hipótesis de que con posterioridad se hubiese modificado el uso. En lo esencial, su respuesta coincide con la de Ofilio y, por lo mismo,

\footnotetext{
34 Que no sería otra que la condictio exercitoria. Sobre el punto, véase VAlIÑo (1968) p. 420. En igual sentido, Cerami (1999) p. 273 (aunque este autor se refiere a ella como actio certae pecuniae exercitoria).

35 Jurista de fines de la República y comienzos del Principado. Kunkel (1967) p. 29 s.; KunKel-SChermaier (2005) p. 140.

36 Jurista del s. I d.C., prefectus urbi en época de Domiciano y Pedio, de época adrianea. Kunkel (1967) p. 133

s. KunKel-Schermaier (2005) p. 88, n. 23.

37 Di PorTo (1984) p. 201, n. 73 cita a este pasaje a propósito del concepto de navis instructa.

38 Pugliese (1957) p. 317, interpreta la respuesta de Ofilio en el sentido de que para este se debía establecer si, al momento del contrato, se había expresado o no una cláusula relativa a la específica destinación del dinero (ad reficiendam navem), de modo que, de haberse pactado dicha cláusula, si no se hubiese cumplido, de todas formas se concedía la acción. Pero si nada acerca de lo mismo se hubiese dicho, entonces la acción no se concedía. Admitiendo una hipótesis interpolacionista, Pugliese agrega que esta perspectiva objetiva habría sido modificada por los compiladores, quienes habrían introducido una perspectiva subjetiva (en el período quod siprobat), de modo de conceder la acción si al momento del contrato el magister quería efectivamente destinar el dinero a la reparación de la nave, siendo irrelevante un posterior cambio en sentido contrario. Coherentemente con esta premisa, los compiladores habrían denegado la acción si al momento de la celebración del contrato hubiese querido el magister navis efectivamente defraudar. Miceli (2001) p. 199, también observa en el pasaje un reforzamiento del elemento objetivo en la determinación de la amplitud de la praepositio. A su vez, esta autora (p. 387) adhiere a la idea de Pugliese, en el sentido de indicar la expresión ad reficiendam navem una declaración formal tendente a imprimir una destinación final a la suma de dinero. LONGO (1972) p. 592 atribuye la expresión distinctio a mano compilatoria.
} 
puede decirse que adhiere a la opinión de este ${ }^{39}$. A su vez, Ulpiano adhiere a Pegaso, y su respuesta no incorpora ningún elemento adicional ${ }^{40}$.

Conviene detenerse en la respuesta de Ofilio. Hay dos motivos importantes para ello: primeramente, el hecho de que ella contiene varios elementos cuya valoración se superpone; en segundo lugar, que su responsum no parece haber encontrado contradictores, lo que la convirtió en la opinión dominante ${ }^{41}$. La primera parte del responsum parece centrarse en la oposición entre el motivo declarado y el acto final de destinación. Si la razón por la cual se pidió en mutuo el dinero concernía a la nave, entonces al mantenerse dicho negocio dentro de los términos del edicto, permitiría conceder la acción. Si, posteriormente, se modificaba el uso este hecho no obstaría al ejercicio de aquella. No se trata, entonces, de una contradicción entre una causa real y una declarada. Se trata, sencillamente, de un acto unilateral -el uso del dinero dado en mutuo- que sobreviene y que no estaba presente al momento del mutuo, y ello no obsta a la tutela del tercero ${ }^{42}$.

Pero tal como viene reportado, el responsum de Ofilio es más extenso, ya que incluye una variante del mismo supuesto y que resulta significativa, en cuanto lleva a una conclusión diferente: se pregunta qué ocurre si desde un principio y con ánimo fraudatorio, el magister navis solicitó el mutuo y no declaró expresamente destinarlo a la reparación de la nave (et hoc specialiter non expresserit, quod ad navis causam accipit). La respuesta de Ofilio es que en tal caso no procede la exercitoria contra el naviero.

En esta variante se dan elementos que contribuyen de modo decisivo a un cambio en la respuesta. De acuerdo con el texto, no parece haber problema con la praepositio del magister navis, así como tampoco con los negocios para los cuales esta se perfeccionó. El problema radica, en primer término, en el ánimo fraudatorio del patrón de nave y, seguidamente, en la ausencia de una declaración expresa de que el dinero se pide en prestamo por causa de la nave. La solución, evidentemente, perjudica al que contrató con el magister navis, pero ello es producto de una ponderación de dos elementos: parecería, por una parte, que el mutuante es engañado, puesto que desde el comienzo el patrón de nave sabe que la destinación de ese dinero no será una inversión en la nave. Pero, por otra parte, el hecho de

39 En general, la romanística, a pesar de reconocer la importancia de la respuesta de Ofilio para la jurisprudencia posterior, no incluye en esta a Pegaso, cuya opinión se analiza sin más relación con la de Ofilio que la de encontrarse recogida en el mismo fragmento. Véase Cerami (1999) p. 274; Miceli (2001) p. 196 y MiCeli (2008) p. 74 ss.

40 Wunner (1964) p. 115, sostiene que la de Pegaso sería tan solo una “interpretación típica” (typische Auslegung), en referencia a un razonamiento de partida al que recurrirían los juristas romanos, ante el supuesto de imprecisa extensión de la praepositio. Esta clase de interpretación, al contrastarse con la voluntad reconocible del dominus termina por ceder ante esta. Véase también: Valiño (1968) p. 419; Coppola BisazZa (2006) p. 198 ss.

41 Véase Cerami (1999) p. 274. Con todo, debe decirse que, en general, la romanística no incluye entre los juristas influidos por Ofilio a Pegaso, cuya opinión se analiza sin más relación con la del primero que la de encontrarse recogida en el mismo fragmento.

42 Cerami (1999) p. 271 ss., enfoca el problema como la posibilidad de imputar -o de no hacerlo- a la praepositio el supuesto del mutuo ad reficiendam navem. A su juicio, Ofilio introduce en su respuesta dos tipos de mutuo: el prestamo de consumo en sentido estricto, circunscrito al ámbito del contrahere, que en el caso de marras no admitiría acción contra el naviero, y el prestamo de financiamiento, reconducible al ámbito del negotiari, que sí la admitiría. 
que el defraudador no explicite que pide el dinero a causa de la nave, debilita la posición del acreedor. Este, en realidad, no es engañado, ya que no se le hace creer que el dinero es para la nave; sencillamente, no es lo suficientemente diligente por cuanto no indaga la finalidad que se dará al dinero y parece contentarse con saber que el mutuario es magister navis. Precisamente, la reticencia de este último para revelar la finalidad del dinero, pone de manifiesto un actuar negligente por parte del mutuante y, por lo mismo, queda impedido de ejercitar la acción contra el naviero. Con ello, el supuesto queda fuera del control de la actio exercitoria y, por consiguiente, queda excluida la responsabilidad in solidum del naviero.

Ulpiano afirma que la distinción sobre la cual se estructura la respuesta de Ofilio fue seguida por Pedio. No indica Ulpiano si él mismo también la sigue y de su silencio podría conjeturarse que sí, dado que una posición en contrario lo habría llevado a exponerla. Sin embargo, la gravitante opinión de Ofilio en torno al primer supuesto descrito, permitió que el razonamiento de Ulpiano pudiera extenderse a uno diferente: el de pedir un mutuo para pagar otro, solicitado, a su vez, por causa de la nave, tal como viene expuesto en: D. 14,1,1,11. Sed si ab alio mutuatus liberavit eum, qui in navis refectionem crediderat, puto etiam huic dandam actionem, quasi in navem crediderit. Se pregunta Ulpiano si en tal caso procede igualmente la acción contra el naviero y su respuesta es positiva. Para Ulpiano casi no hay diferencia entre uno y otro mutuo, en la medida que ambos tienen que ver con la nave; de ahí que argumente con una comparación: quasi in navem crediderit.

\subsection{La CONFIRMACIÓN DE QUE PARA LA JURISPRUDENCIA CLÁSICA NO ERA INDIFERENTE LA DILIGENCIA DEL MUTUANTE COMO ELEMENTO A CONSIDERAR PARA DECIDIR LA CONCESIÓN DE LA ACCIÓN, LA OFRECE UN PASAJE DE AFRICANO: \\ D. 14,1,7pr.-2 (Afric. 8 quaest.): Lucius Titius Stichum magistrum navis praeposuit:} is pecuniam mutuatus cavit se in refectionem navis eam accepisse: quaesitum est, an non aliter Titius exercitoria teneretur, quam si creditor probaret pecuniam in refectionem navis esse consumptam. respondit creditorem utiliter acturum, si, cum pecunia crederetur, navis in ea causa fuisset, ut refici deberet: etenim ut non oportet creditorem ad hoc adstringi, ut ipse reficiendae navis curam suscipiat et negotium domini gerat (quod certe futurum sit, si necesse habeat probare pecuniam in refectionem erogatam esse), ita illud exigendum, ut sciat in hoc se credere, cui rei magister quis sit praepositus, quod certe aliter fieri non potest, quam si illud quoque scierit necessariam refectioni pecuniam esse: quare etsi in ea causa fuerit navis, ut refici deberet, multo tamen maior pecunia credita fuerit, quam ad eam rem esset necessaria, non debere in solidum adversus dominum navis actionem dari. (1) Interdum etiam illud aestimandum, an in eo loco pecunia credita sit, in quo id, propter quod credebatur, comparari potuerit: quid enim, inquit, si ad velum emendum in eiusmodi insula pecuniam quis crediderit, in qua omnino velum comparari non potest? et in summa aliquam diligentiam in ea creditorem debere praestare. (2) Eadem fere dicenda ait et si de institoria actione quaeratur: nam tunc quoque creditorem scire debere necessariam esse mercis comparationem, cui emendae servus sit praepositus, et sufficere, si 


\section{in hoc crediderit, non etiam illud exigendum, ut ipse curam suscipiat, an in hanc rem pecunia eroganda est ${ }^{43}$.}

El contenido del problema no parece diferir demasiado, al menos en principio, del anterior: el patrón de nave pidió dinero para reparar la nave y ahora se pretende demandar al naviero. Pero se consulta al jurista -Juliano, con toda probabilidad ${ }^{44}-$ si acaso el demandante debe probar que el dinero se invirtió efectivamente en la reparación de la nave, o bien -el corolario es obligado- le bastaría con probar el mutuo al patrón de nave $e^{45}$. Juliano parece convencido de que el segundo de estos extremos no bastaría para el éxito de la demanda; se sigue esta convicción de tomar en consideración al primero de los extremos en cuestión. Juliano subraya en su responsum el criterio de la pertinencia del mutuo: si se pidió dinero para reparar la nave, es exigible que haya existido la necesidad de tal reparación. Desecha que sea exigible al acreedor probar que el dinero se empleó efectivamente en reparar la nave; ello equivaldría, dice Juliano, a exigirle al mutuante gestionar el negocio del naviero, lo que parece excesivo. Pero sí cree posible exigir al acreedor que esté al tanto de los

43 Trad.: "Lucio Ticio puso como patrón de nave a Estico. Este recibió dinero en mutuo y convino que lo había recibido para reparar la nave. Se preguntó si no quedaría Ticio obligado por la acción exercitoria, a menos que el acreedor probase que el dinero se invirtió en la reparación de la nave. (Juliano) respondió que el acreedor ejercitará útilmente la acción si, al momento de ser mutuado el dinero, la nave hubiese estado en situación que debiese ser reparada. Porque así como no conviene que el acreedor sea obligado a cuidar que la nave sea reparada, y sea gestor del negocio del dueño, lo que ciertamente habría de suceder si tuviera necesidad de probar que el dinero se gastó en reparación, así también se ha de exigir esto, que él sepa que presta para aquella cosa para la que cualquiera haya sido puesto como patrón; lo que verdaderamente no puede suceder de otro modo que si también supiere esto, que es necesario el dinero para la reparación. Por lo cual, aunque la nave se hubiese hallado en estado de que debiera ser reparada, pero se hubiese prestado una cantidad mucho mayor de dinero de la que para tal objeto fuese necesaria, no debe darse por todo acción contra el dueño de la nave. (1) A veces también se ha de apreciar esto, si se hubo prestado el dinero en aquel lugar en que haya podido comprarse aquello para lo que se prestaba; porque ¿qué se determinará, dice, si alguno hubiese prestado el dinero para comprar una vela en isla tal, que en ella no puede absolutamente comprarse vela alguna? Y, en suma, que en este particular el acreedor debe prestar alguna diligencia. (2) Añade que se ha de decir casi lo mismo si se tratara de la acción institoria, porque también entonces debe saber el acreedor que era necesaria la compra de mercancía, para cuya compra haya sido destinado el esclavo, y que basta, si hubiese prestado para esto. Y que no se ha de exigir también que él mismo tome a su cargo el cuidado de si el dinero se gastó en aquella cosa". La traducción de cavit por "convino" hace suya la interpretación que a la misma diese PugLIESE (1957) p. 318 s., por oposición a la de De Martino (1941) p. 12, quien sostenía que se trataba, más bien, de una cautio (ad reficiendam navem). Aunque Pugliese no desconoce que el verbo cavere indica, por regla general, la celebración de una stipulatio, sostiene que aquí, en cambio, haría referencia a una lex del mismo tipo de la que hablaba Ofilio, "es decir, una declaración que hace parte del contrato específico, con la cual el magíster no tanto se obligaba a utilizar la suma en la reparación de la nave, cuanto afirmaba haberla recibido con tal fin”. De la misma opinión es MiCeli (2007) 386 ss. y Miceli (2008) p. 75. A favor de la interpretación de De Martino se manifestó LONGO (1972) p. 593 s.

44 La obra de Africano, Quaestiones, es la única que se conserva en el Digesto de este jurista, a pesar de que algunas fuentes le atribuyen alguna otra. De él se sabe que fue discípulo de Salvio Juliano, lo que ha motivado cierta controversia entre los romanistas en torno a la doctrina contenida en su obra. Algunos sostienen que no se trata más que de doctrina julianea, en tanto otros postulan una mayor autonomía. D’Ors (1997, p. 15) propone el siguiente método: debe entenderse una referencia a Juliano i) cuando es citado expresamente; ii) cuando no dice su nombre, pero utiliza ciertos verbos conjugados en tercera persona, tales como ait o respondit (como es, precisamente, el caso aquí) y otros verbos similares, y iii) cuando usa el estilo indirecto con oración de infinitivo.

45 Aubert (1994) p. 60. 
negocios para los cuales se nombró al magister navis (ut sciat in hoc se credere, cui rei magister quis sit praepositus) y que este conocimiento no es independiente del hecho de constarle que el dinero es necesario para la reparación. Más aún, en el $\$ 1$ refuerza Juliano este deber del mutuante, al sostener que debe, además, creer en la posibilidad de comprar lo que la nave necesita en el mismo lugar en que se concede el prestamo ${ }^{46}$.

De lo anterior, Juliano extrae una regla: la cantidad prestada no puede ser mayor a la necesitada. De este modo, si se prestase más dinero que el que realmente era necesario para reparar la nave, entonces, la exercitoria no permitiría exigir el exceso. De este modo, Juliano une la concesión de la acción al conocimiento por parte del mutuante de la necesidad de reparación de la nave, a los términos de la praepositio y al cálculo del dinero necesario para el mismo. A juicio de Valiño, de la declaración del mutuario dependerá el tipo de acción, ya que si la ha habido por parte del magister, corresponderá la condictio exercitoria; en cambio, si nada ha declarado, al mutuante no le quedaría más que inferir que el prestamo no entra en la praepositio "y solo le resta la posibilidad de demandar de peculio" ${ }^{47}$.

\subsection{A pRopósito de LA aCtio institoria, Un RAZONAMIENTO Similar PUEde} OBSERVARSE EN OTRO TEXTO ULPIANEO, A SABER:

D. 14,3,13pr. (Ulp. 28 ad ed.): Habebat quis servum merci oleariae praepositum Arelatae, eundem et mutuis pecuniis accipiendis: acceperat mutuam pecuniam: putans creditor ad merces eum accepisse egit proposita actione: probare non potuit mercis gratia eum accepisse. licet consumpta est actio nec amplius agere poterit, quasi pecuniis quoque mutuis accipiendis esset praepositus, tamen Iulianus utilem ei actionem competere ait ${ }^{48}$.

El caso debió ser tratado primeramente por Juliano, jurista cuya opinión es citada al final del fragmento, y a él cabe atribuir la doctrina contenida en el pasaje. Se trata de un caso de prestamo que recibe un institor de parte de un mutuante, quien, en lugar de corroborar que el dinero mutuado se invertirá en la mercancía, sencillamente presume que será asís ${ }^{49}$. En este sentido, el centro de gravedad del pasaje es la actitud pasiva del acreedor,

\footnotetext{
46 Véase Miceli (2008) p. 74 ss.

47 VALIÑo (1968) p. 420. Aunque nuestro autor no aclara su opción por la acción de peculio, podría sostenerse que la inferencia a la que hace referencia no resulta tan obvia: la acreditación de la existencia de un peculio, algo por lo demás incierto, no tendría por qué se más ventajosa o menos difícil que la prueba de actos que supongan conocimiento o voluntad. D’Ors (1997) p. 348 s. acoge la interpretación de Valiño. A juicio de este último, esta acción sería más riesgosa para el actor, ya que si, efectivamente no se hubiese invertido en la nave, no habría un enriquecimiento, es decir, faltaría el supuesto fáctico de la in rem verso.

48 Trad.: "Tenía uno un esclavo encargado del comercio de aceite en Arlés y de recibir él mismo cantidades en mutuo, y había recibido dinero en mutuo. Juzgando el acreedor que aquel lo recibió para mercancías ejerció la acción propuesta; no pudo probar que lo recibió para la mercancía y, aunque se extinguió la acción -y no podrá volver a demandar-, como que hubiese sido encargado también de recibir en mutuo, sin embargo, dice Juliano que le compete la acción útil”.

49 Una interesante exégesis del pasaje, sobre todo en punto a la actio utilis de la cual se habla, en VALIÑo (1967), pp. 365 ss., reafirmada en VAliño (1974) p. 316 s. En este último trabajo el autor desecha la posibilidad de que se trate de una actio ad exemplum institoriae y propone, en cambio, una condictio institoria con carácter de útil, el que vendría dado -de acuerdo con la tesis defendida en el trabajo al que hacemos referencia- de que su fórmula contendría una ficción. En efecto, si la praepositio principal no se refería a prestamos, para efectos de exigir una deuda nacida de un mutuo, el pretor habría incluido en la fórmula
} 
quien se limita a suponer (putans creditor) aquello que, en opinión de Juliano, debía comprobar, esto es, que el dinero prestado se recibe a causa de la mercancía. Aunque la acción institoria se consume, Juliano le concede la institoria utilis. Esta última circunstancia marca una diferencia con el caso previsto en D. 14,1,7pr., en que no se concede esta acción. La razón debería encontrarse en el hecho de que en el caso del institor de Arlés, este estaba encargado de dos clases de negociaciones: de una parte, la venta de aceite y, de otra, la de recibir cantidades en prestamo. La causa del ejercicio de la institoria habría sido la primera, es decir, la venta de aceite. Pero, debido a que no pudo probar que el dinero fuese destinado a comprar aceite, Salvio Juliano le concede la acción útil, amparándose en la segunda clase de negociaciones establecida en su praepositio, es decir, recibir dinero en prestamo ${ }^{50}$. Con todo, es suficientemente clara la opinión de Juliano en el sentido de exigir del mutuante de un institor el corroborar la necesidad del prestamo que solicitaba ${ }^{51}$.

Los fragmentos analizados permiten ubicar en la jurisprudencia clásica alta un aspecto de no poca importancia: el de la delimitación funcional de la responsabilidad contractual del naviero, relacionada con el objeto de la negociación. En efecto, Johnston, tratando de encontrar una explicación a los requerimientos que Juliano hace al mutuante, en D. 4,1,7pr.-2, sostuvo que el jurista se habría inclinado a conceder la acción, pero solo dentro de ciertos límites. El fundamento estribaría radicaría en la contradicción que acción supondría con un principio fundamental en materia de contratos, al tiempo que exponía al dueño a una responsabilidad ilimitada. De ahí que, además, la concesión de esta acción estuviese relacionada con la comprobación -llevada adelante por el acreedor- de que el prestamo se concedía para un objetivo necesario para el negocio ${ }^{52}$. En referencia a D. 4,1,1,8-9, Cerami ${ }^{53}$ apunta en una dirección similar, al sostener que si bien la cláusula de destinación (ad reficiendam navem) es indispensable, no es suficiente presupuesto de la responsabilidad del exercitor, lo que tiene por resultado "una significativa limitazione della responsabilità dell'armatore" (CERAmi, 1999, p. 275 s.).

En síntesis, el mutuo, en la medida en que era contraído por causa de la nave, a un magister navis, fue reconocido tempranamente como uno de aquellos negocios jurídicos que justificaban la concesión de las acciones exercitoria e institoria. Sin embargo, si no resultaban suficientes para tal efecto los términos de la praepositio, era menester entonces la comprobación de que la causa del mutuo se relacionaba estrechamente con la gestión de la

\footnotetext{
la ficción quasi pecuniis quoque mutuis accipiendis esset praepositus, lo que habría permitido al juez eludir la insuficiencia de la praepositio.

50 García Garrido (2001) p. 51. Valiño (1967) 374, después de analizar la posición de otros autores, conjetura que debía tratarse de solo una praepositio, principalmente para el comercio de aceite, más otra complementaria, para recibir dinero en prestamo.

51 Aubert (1994) p. 14, cita este pasaje, así como varios otros, en n. 47, en apoyo de una afirmación que hace a propósito de D.14,5,8. A juicio de Aubert la institoria se denegaba ahí donde la negociación llevada adelante por el factor excedía los límites a que lo autorizaba su praepositio. Si esta es la conclusión para D.14,5,8, ella no puede ser extendida sin más a D.14,3,13pr., puesto que aquí la acción institoria no es simplemente denegada, sino que el procedimiento incluso sobrepasa la litis contestatio, lo que explica la indicación del jurista de que ella se había consumido (consumpta es actio).

52 Johnston (1994) p. 1521.

53 Cerami (1999) p. 275 ss.
} 
nave o de la empresa. Y en este plano, la diligencia del mutuante resultaba clave, al punto que la actitud contraria tendría por efecto impedir el ejercicio de la acción.

\section{CONCLUSIONES}

He querido centrar mi atención en la forma en que la jurisprudencia debió hacerse cargo de una específica cláusula de los edictos en que se prometían las acciones exercitoria e institoria: eius rei nomine. Sobre la base de que la sola praepositio no habría bastado para legitimar pasivamente a las acciones exercitoria o institoria al empresario naviero o terrestre, los juristas desarrollaron una práctica interpretativa de dicha cláusula que, progresivamente, dio importancia a nuevos elementos. Ello dio lugar a una rigurosa diferenciación entre aquellos supuestos que admitían la responsabilidad adyecticia de aquellos que no. La dación mutuaria sirve de ejemplo, en este caso, para observar cómo la jurisprudencia discute en distintos niveles un mismo problema e introduce variantes que ponen a prueba la justicia de la decisión. Este último aspecto, me parece, debió ser decisivo, por la siguiente razón: la distancia temporal del edicto llevaba consigo la de aquella gestión negocial que el pretor habría pretendido abarcar. Pero los juristas parecieron advertir que, en la misma medida en que se alejaban de un modelo inicial de actuaciones, aumentaban las posibilidades para dudar si un determinado negocio era o no de aquellos previstos en la praepositio. Y, como ha sido observado, contribuía -y mucho- a esta tensión la redacción del propio edicto, amplia y, por consiguiente, abarcadora de un número indeterminado de supuestos.

Vinculado a lo anterior, es posible observar cierta insistencia en época tardoclásica, por describir o identificar supuestos típicos de negocios jurídicos que permitían conceder la acción. Tal práctica interpretativa apuntaría, en mi opinión, en dos direcciones complementarias: la primera y más obvia sería la de acentuar la importancia del contenido de la cláusula eius rei nomine, cui praeposuerit fuerit, es decir, de la exacta consistencia entre el específico negocio jurídico concluido por el magister navis o el institor y aquel genérico elenco de actos señalados en la praepositio. La segunda, menos obvia, tendría que ver con una toma de posición por parte de Ulpiano ante ciertas discusiones de las que se había ocupado la jurisprudencia anterior. Ante este escenario, el jurista tardoclásico habría optado por tender hacia la tipificación contractual, en el sentido de conceder preeminencia a elementos objetivos por sobre otros de carácter subjetivo. Finalidad última de todo aquello habría sido delimitar el exacto ámbito de aplicación de las acciones exercitoria e institoria, valiéndose para ello de criterios predominantemente objetivos. La necesidad de evaluar la aplicación del edicto a las diferentes circunstancias en que ocurría la negociación alcanzaría así, en Ulpiano, un último estadio de elaboración dogmática.

\section{BIBLIOGRAFÍA CITADA}

Aubert, Jean-Jacques (1994): Business Managers in Ancient Rome. A Social and Economic Study of Institores, 200 B.C. - A.D. 250 (Leiden-New York-Köln, E.J. Brill).

Cerami, Pietro (1999): "Mutua pecunia a magistro 'navis reficiendae causa' sumpta e 'praepositio exercitoris", en Ruedin, Roland (edit.), Mélanges en l'honour de Carlo Augusto Cannata (Bâle - Genève- Munich, Helbing \& Lichtenhahn) pp. 271-279. 
Cerami, Pietro y Petrucci, Aldo (2010): Diritto commerciale romano. Profilo storico (Torino, Giappichelli, terza edizione).

Coppola Bisazza, Giovanna (2006): "Alcune riflessioni in tema di exercitor e di actio exercitoria”, en la Torre, U., Moschella, G., Pellegrino, F., Rizzo, M.P., Vermiglio, G. (a cura di): Studi in memoria di Elio Fanara, t. I (Milano, Giuffrè) pp. 189-202.

De LigT, Luuk (1999): "Legal History and economic history: the case of the actiones adiecticiae qualitatis", Tijdschrift voor Rechtsgeschiedenis, Vol. 67, No 3: pp. 205-226.

De Martino, Francesco (1941): "Studi sull'actio exercitoria", Rivista di Diritto della Navegazione, Vol. 7: pp. 7-31.

Di Porto, Andrea (1984): Impresa collettiva e schiavo 'manager' in Roma antica (Milano, Giuffrè).

Domingo, Rafael (1992): Estudios sobre el primer titulo del edicto pretorio, tomo I (Santiago de Compostela, Universidad de Santiago de Compostela).

GARCía GARRIDO, Manuel (2001): El comercio, los negocios y las finanzas en el mundo romano (Madrid, Dykinson).

García Garrido, Manuel (2010): "Responsabilidad in solidum en la casuística de la actio exercitoria”, en Russo Ruggeri, Carmela (a cura di), Studi in onore di Antonino Metro, tomo III (Milano, Giuffrè) pp. 1-15.

GuZMán Brito, Alejandro (2005): Acto, negocio, contrato y causa en la tradición del Derecho europeo e iberoamericano (Cizur Menor, Thomson Aranzadi).

HaCKL, Karl (1999): “Vom 'quasi' in römischen zum 'als ob' im modernen Recht”, en ZIMMERMann, Reinhard (Hsg.), Rechtsgeschichte und Privatrechtsdogmatik (Heidelberg, C.F. Müller) pp. 117-127.

Johnston, David (1994): "Limiting Liability: Roman Law and the Civil Law Tradition", Chicago-Kent Law Review, Vol. 70, No 4: pp. 1515-1538.

Kaser, Max (1971): Das römische Privatrecht. Erster Abschnitt. Das altrömische, das vorklassische und klassische Recht (München, Beck, segunda edición).

Kaser, Max (1975): Das römische Privatrecht. Zweiter Abschnitt: Die nachklassischen Entwicklungen (München, Beck, segunda edición).

Kunkel, Wolfgang (1967): Herkunft und soziale Stellung der römischen Juristen (Graz Wien - Köln: Böhlau, segunda edición revisada y aumentada).

Kunkel, Wolfgang y Schermaier, Martin (2005): Römische Rechtsgeschichte (Köln - Weimar - Wien, Böhlau, decimocuarta edición).

LENEL, Otto (1896): "Handeln in fremdem Namen und die actiones adiecticiae qualitatis", Jherings Jahrbücher für die Dogmatik des bürgerlichen Rechts, Vol. 36: pp. 131-144.

Lenel, Otto (1927): Das Edictum Perpetuum (Leipzig, B. Tauchnitz).

Longo, Giannetto (1972): "Actio exercitoria - actio institoria - actio quasi institoria”, en BisCardi, Arnaldo (a cura di), Studi in onore di Gaetano Scherillo, tomo 2 (Milano, Istituto Editoriale Cisalpino - La Goliardica) pp. 581-626.

Miceli, Maria (2001): Sulla struttura formulare delle 'actiones adiecticiae qualitatis' (Torino, Giappichelli).

Miceli, Maria (2002): "Institor e procurator nelle fonte romane dell'età preclassica e classica”, IVRA, Vol. 53: pp. 57-176. 
Miceli, Maria (2008): Studi sulla "rappresentanza" nel diritto romano, tomo I (Milano, Giuffré).

Miceli, Maria (2007): "L'actio institoria e l'azione concessa al proponente contro i terzi che hanno negoziato con un preposto libero", en VV.AA., Studi per Giovanni Nicosia, tomo V (Milano, Giuffrè) pp. 369-403.

Ors, Álvaro d', Hernández Tejero, Francisco, Fuenteseca, Pablo, García Garrido, Manuel, y Burillo, Jesús (1968): El Digesto de Justiniano (Pamplona, Aranzadi).

Ors, Álvaro d' (1997): Las 'Quaestiones' de Africano (Roma, Pontificia Università Lateranense - Mursia).

Ors, Álvaro d' (1998): Las Instituciones de Gayo, en Domingo, Rafael (director), Textos de Derecho romano (Pamplona, Aranzadi), pp. 39-245.

Petrucci, Aldo (2007): Per una storia della protezione dei contraenti con gli imprenditori (Torino, Giappichelli).

Pugliese, Giovanni (1957): "In tema di actio exercitoria", Labeo, Vol. 3: pp. 308-343.

Serrao, Feliciano (1971): s.v. "Institore", Enciclopedia del Diritto, Vol. 21 (Milano, Giuffrè) pp. 827-833.

SerraO, Feliciano (1989): Impresa e responsabilità a Roma nell'età commerciale (Pisa, Pacini).

ValiÑo, Emilio (1967): "Las 'actiones adiecticiae qualitatis' y sus relaciones básicas en Derecho romano", Anuario de Historia del Derecho Español, Vol. 37: pp. 339-436.

VALiño, Emilio (1968): «Las relaciones básicas de las acciones adyecticias», Anuario de Historia del Derecho Español, Vol. 38: pp. 377-480.

VALIÑo, Emilio (1974): Actiones utiles (Pamplona, EUNSA).

WaCKE, Andreas (1994): "Die adjektizischen Klagen im Überblick (I). Von der Reederund der Betriebsleiterklage zur direkten Stellvertretung”, Zeitschrift der Savigny Stiftung. Romanistische Abteilung, Vol. 111: pp. 280-362.

Wunner, Sven Erik (1964): Contractus. Sein Wortgebrauch und Willensgehalt im klassischen römischen Recht (Köln-Graz, Böhlau). 